\title{
La desnaturalización del contrato de empleo público
}

\section{FERNANDO LUJÁN-AcostA ${ }^{1}$}

\section{RESUMEN}

El presente artículo trata el contrato de empleo público desde dos perspectivas: teórica doctrinaria y jurídica normativa. La problemática que aborda refiere a las modificaciones del contrato de empleo público, esencialmente en la década del 90 del pasado siglo a partir de la transformación, reforma y crisis del Estado argentino. La progresiva y sistemática aplicación de normas y mecanismos laborales a partir de los procesos citados ha impactado en el tipo de contrato objeto de estudio desnaturalizándolo, debido a que sigue estando bajo la égida del Estado. La hipótesis de la desnaturalización, propuesta en este artículo, permite una mirada holística en relación a la problemática del empleo público.

Palabras clave: contrato de empleo público, función pública, desnaturalización, flexibilización, precarización, transformación del Estado.

\section{Denaturation of public employment}

\author{
ABSTRACT \\ This paper deals with the Public Employment Contract from two perspecti- \\ ves: a theoretical doctrinal perspective and a legal regulatory perspective. It
}

1 Doctor en Ciencias Jurídicas, Pontificia Universidad Católica de Argentina, Buenos Aires, Argentina. Profesor de Derecho Administrativo, Universidad Nacional de la Matanza (UNlaM), Buenos Aires, Argentina. Correo-e: fernando@unlam.edu.ar Fecha de recepción: 15 de julio de 2015. Fecha de modificación: 24 de septiembre de 2015. Fecha de aceptación: 10 de octubre de 2015. Para citar el artículo: LuJÁN-ACOSTA, F. (2015). Desnaturalización del contrato de empleo público. Revista Digital de Derecho Administrativo n. ${ }^{\circ} 14$, Universidad Externado de Colombia, pp. 195-220. DOI: http://dx.doi.org/10.18601/21452946.n14.10 
addresses the problem of modifications to the public employment contract, mainly in the 1990s starting after Argentina's economic transformation, reform and crisis. The gradual and systematic application of labor standards and norms arising from this crisis has impacted and denaturized these types of contract due to the fact that it remains under the aegis of the State. This article proposes a hypothesis of denaturation which provides for a holistic view of public employment.

Keywords: Public employment, denaturation, relaxation, precariousness, transformation of the State.

\section{INTRODUCCIÓN}

El avance en general del derecho privado sobre el contrato administrativo de empleo público significó una modificación, no solo de él mismo sino también de otras instituciones del derecho público. Si el derecho privado privilegia los derechos del particular, el público se basa en el bien común.

El Estado desarrolla su actividad a través de cierto tipo de contratos (de empleo público y de obra, entre otros) pero, en líneas generales, en relación al contrato de empleo público desde el punto de vista del derecho público, los europeos hablan de una huida del derecho público al privado.

Afirmamos con Dromi (2006, p. 588) que el "empleo público es una relación contractual de derecho público, que guarda analogía, en cuanto a su objeto, con el contrato de trabajo y con la locación de servicios, pero que difiere de ellos, por el régimen jurídico específico en razón de ser el Estado el contratante y en razón de los fines del servicio contratado".

El Estado, en todos sus niveles, en cumplimiento del mandato del preámbulo de la Constitución Nacional en el caso del Estado Argentino, debe propender a materializar el objetivo de promover el bienestar general, mejorando la calidad de vida de sus ciudadanos, y satisfacer condiciones básicas e indispensables para una convivencia acorde, rigiendo a la vez los vínculos entre los mismos individuos y las relaciones que se producen entre estos últimos y el propio Estado.

Es en este sentido y por estas razones que surge la idea de que tales cometidos deben llevarse a cabo de manera independiente del partido político que circunstancialmente se encuentre en el poder y, en consecuencia, en diferentes países y en forma progresiva, se fue reconociendo dentro de la esfera pública la necesidad de que sus trabajadores gocen de estabilidad en el empleo, superándose la vieja práctica del botín.

Por su parte, aquellas personas que deseen pertenecer al aparato burocrático del Estado deben cumplir ciertas condiciones y requisitos para acceder y permanecer en él y, cumplidos ellos, adquieren determinados derechos. 
El fenómeno administrativo cambia continuamente de cauce porque el objeto de estudio -la Administración Pública- también lo hace, en la medida que el Estado del que forma parte se transforma de manera permanente. Pero, el factor más determinante que modificó la dinámica de la última década del siglo XX fue la globalización, la cual no solo ha cambiado la organización económica sino también la estructura y organización jurídica.

García Pulles (2005), Ivanega (2009), Comadira (2003), Capón Fila (2006) y Cassagne (2010), entre otros, refieren un proceso de laboralización respecto del empleo público que se registra desde hace años en el ámbito internacional.

La propuesta del presente artículo es exponer, en parte, los resultados de una investigación que se trazó como objetivo demostrar que los fenómenos acaecidos en el ámbito del empleo público en general, y particularmente en el caso del empleo del no docente de las universidades nacionales de la República Argentina en la década de 1990, provocaron un proceso de desnaturalización.

Para cumplir con ese objetivo se ha identificado, sistematizado y analizado la normativa internacional, regional y nacional y la jurisprudencia del período relacionada con nuestro objeto de estudio.

Pero la prueba no hubiera sido posible si no se hubiese analizado el proceso de transformación, reforma y crisis del Estado argentino que ha impactado en la modificación del cumplimiento de principios y normas básicas legales cuya consecuencia inmediata fue la "flexibilización" tanto en el ámbito privado como en la esfera del empleo público.

En este sentido se han desarrollado una serie de conjeturas, seleccionando para este artículo aquellas concernientes al bloque de legalidad y a la cuestión del Estado.

A partir de la investigación citada podemos afirmar que la desnaturalización posibilita la comprensión del fenómeno en su totalidad, mientras que los planteos de laboralización, precarización, privatización hacen referencia a sus efectos. Esta perspectiva holística abre de este modo una línea de análisis teórico en el área del derecho administrativo.

\section{DESARROLLO}

Para un mejor ordenamiento en el abordaje de esta temática se considera oportuno establecer un conjunto de argumentos conjeturales que hacen referencia a las ideas medulares de la hipótesis de la desnaturalización, deteniéndome a posteriori en la explicación de cada una de ellas.

1. El proceso de desnaturalización se debe a la pérdida de la esencia de lo público en el marco del fin del Estado debido a que el mismo -siendo una de las partes del contratoes la comunidad perfecta en la que se desarrolla el bien común. 
2. La transformación de la estructura del Estado, teniendo en cuenta la actuación del principio de subsidiariedad, ba conllevado una modificación en la estructura burocrática pública, impactando en las relaciones de los ámbitos público y privado y de sus derechos correspondientes, pero no en la esencia del Estado.

3. La mutación del bloque de legalidad referido al empleo público debido a la incorporación de normas del derecho privado, es solidaria con el proceso de desnaturalización precitado.

4. Los procesos que la doctrina ba denominado de laboralización, flexibilización y precarización del empleo público explican las consecuencias de la incorporación de las normas del derecho privado en el ámbito del empleo público.

\section{PRIMER ARGUMENTO}

El proceso de desnaturalización se debe a la pérdida de la esencia de lo público en el marco del fin del Estado debido a que el mismo - siendo una de las partes del contrato-es la comunidad perfecta en la que se desarrolla el bien común.

Este primer argumento profundiza la cuestión del Estado haciendo hincapié en los fines del mismo.

Asumimos con Cassagne (2003) que las ideas acerca de la configuración histórica y política del Estado han ido variando a través del tiempo sin que apareciera, hasta el final de la Edad Media, un concepto que tradujera, con un alcance general, su expresión jurídica e institucional. Resulta ineludible recurrir entonces al pensamiento de Santo Tomás de Aquino, para quien el Estado es una institución por derecho propio, es una communitas perfecta teniendo a disposición todos los medios necesarios para la consecución de su propio fin, el bien común.

En el marco de las ciencias sociales, Di Tella (2001, p. 233) atribuye el uso del término, a modo de neologismo -que data de Maquiavelo-, a un conjunto que abarca desde "la polis griega al walfare state, desde las sociedades primitivas de Asia y África hasta las superpotencias de la era nuclear, aunque más modernamente, ha resurgido la vieja tesis de aplicar el término a un objeto cultural determinado, situado en el tiempo y en el espacio: desde el renacimiento o antes, en Europa Occidental".

Pero la teoría del Estado - siguiendo esta misma síntesis de Di Tella- se difundió ampliamente en Alemania y luego en Francia, no obstante haber generado resistencias en la moderna ciencia política, por razones culturales, políticas y científicas ideológicas. Las ciencias sociales actuales han condensado en la significación del concepto en cuestión planteos que pueden ser agrupados desde los más restringidos a los más amplios, señalando que el Estado es considerado: como una unidad de acción o unidad de autoridad de decisión; como los principios organizadores que dan totalidad a las múltiples y diversas agencias de gobierno; como los principios estructurales que definen y constituyen las relaciones sociales de poder y control político de la sociedad; 
como la estructura duradera de gobierno y mando en la sociedad, o como el ordenamiento jurídico tanto en sentido de jure como de facto; finalmente y en el sentido más amplio, como orden normativo dominante en la sociedad.

En esta lógica del concepto, Di Tella (2001, p. 234) propone la definición del argentino Fayt, quien define la citada institución como "la organización del poder político dentro de una comunidad nacional". Su estructura se compone del poder, del ordenamiento jurídico, de la población y del territorio. La soberanía y el imperio de la ley proporcionan significación y sentido a la estructura.

Cabe señalar que el término Estado no solo es de difícil precisión, sino que además se ve en él implicada una multiplicidad de significados en el devenir temporal. En cada país se postula la existencia real o ficticia de un Estado pero, según los acuerdos actualmente existentes en la ciencia política, la definición de Estado según la síntesis de Pinto (1995), contiene similares características a la definición de Fayt, no obstante un planteo temporo-espacial. En este sentido, se hace referencia a una forma particular de ordenamiento político que surgió en Europa a partir del siglo XIII y hasta fines del XIX o principios del XX, que aún se mantiene y que se ha ido extendiendo a lo largo del tiempo a casi todo el planeta, caracterizada por: soberanía, territorio, conformación de un aparato administrativo de naturaleza burocrática, progresiva centralización de poder, progresiva impersonalidad de mando y secularización de la política.

En el Estado moderno cobra un carácter protagónico la conformación de la burocracia pública. Ella se constituye en un régimen específico que se diferencia del régimen común, consistente en el contrato civil del arrendamiento de servicios (Parada, 2007, p. 12). Cabe señalar asimismo que la comunidad científica social pondrá en Max Weber la explicación del proceso de surgimiento del Estado moderno y la formulación de su definición que hace referencia a una asociación de tipo institucional, que en el interior de un territorio ha monopolizado la coacción física legítima como instrumento de dominio. Basado en el derecho racional o formal proveniente del derecho romano, se explica además el surgimiento del cuerpo administrativo burocrático.

En el escenario del mundo contemporáneo se puede afirmar que fue a partir de la segunda mitad del siglo XX que se dio un proceso de transformación del papel del Estado en respuesta a las exigencias de la realidad y apoyada por el derecho de las comunidades europeas. Según Cassagne (2003, pp. 67 ss.), en Hispanoamérica dicha transformación llevó a la reforma del Estado durante la década de 1990, a causa del endeudamiento externo, el aumento de la burocracia estatal y la ineficiencia de los servicios públicos, entre otras. Paralelamente, se desencadena un proceso de transferencia de empresas y bienes del Estado hacia los particulares, privatizándose inclusive aquellas prestaciones que se engloban bajo la figura del servicio público. La consecuente quiebra del Estado benefactor, sumada a los reclamos por una mayor libertad económica, que sea 
susceptible de permitir el desarrollo espontáneo de la iniciativa privada, se canaliza en las políticas oficiales a través de medidas como las desregulaciones.

El planteo del jurista es de suma importancia porque en su definición de Estado reconoce el imperio del bien común. En efecto, afirma que "el modelo de Estado será ahora de tipo subsidiario a través del cual se encauza la realización del bien común, con predominio del Derecho Público en las estructuras $y$ procedimientos de las funciones indelegables $y$, con recurrencia a formas privadas o mixtas para la actividad supletoria, conforme al objeto perseguido en cada caso" (Cassagne, 2003, p. 67).

El Estado, teniendo en cuenta la actuación del principio de subsidiariedad, ha conllevado una modificación en la estructura burocrática pública a causa de los procesos de privatización mencionados, poniendo en jaque la relación Estado-burocracia. El Estado moderno, surgido de la burocracia, mantiene su finalidad, pero entre la Administración Pública y los burócratas se insertan ahora las asociaciones de los particulares y, en consecuencia, el derecho privado.

El sociólogo Rosanvallon (2009, pp. 101 ss.) define la actualidad como la era de la particularidad, en la que el objetivo se orienta a darle a cada uno medios verdaderamente adecuados para la solución de un problema específico. El desarrollo de una sociedad de la particularidad da lugar a terceros que intervienen. Es decir, a la tercerización y a la flexibilidad. El nuevo Estado posmoderno, según palabras de Rosanvallon (2009, p. 110), se delinea por la negociación, y por lo tanto el saber económico desvaloriza la figura del funcionario, cuya centralidad viene a ser desestabilizada.

La escena de fondo es la globalización, en la que, según aprecia Vallespín (2000, pp. 21 ss.), partiendo de un sustento material, devienen formas de organizaciones más complejas y desterritorializadas en un proceso signado por la revolución digital, la globalización financiera y la consecuente aparición del turbo capitalismo, que a su vez implica una nueva división del trabajo y el crecimiento de la flexibilidad laboral. Estas nuevas caracterizaciones del Estado explican diversas caras de su gran transformación.

El contexto citado implicó el desarrollo de diversas reformas de los Estados particulares. En Argentina dichas reformas se llevaron a cabo por la Ley 23.696/89 y el Decreto 660/96 por el que se modifica la estructura de la Administración Pública Nacional.

El modelo de Estado neoliberal resulta una precondición para poder refinanciar sus deudas y recibir nuevo financiamiento externo.

Según Sidicaro (2003), ese estado de cosas devino en una profunda crisis debido a la pérdida o debilitamiento de las capacidades políticas, burocráticas y administrativas. Swampa (2005), por su parte, en una mirada retrospectiva, afirma que en Argentina se reconocen procesos y cambios políticos basados en el principio de la recurrencia al mercado (principio de subsidiariedad). Su punto de partida es la década de 1970, el cual es sellado con la reforma administrativa de la última década del pasado siglo. 
En el contexto descrito, si bien el fin del Estado sigue siendo el mismo, es decir, el bien común, la esencia de lo público, en virtud de las transformaciones citadas, es vaciada de contenido.

\section{SEgUndo ARGUMENTO}

La transformación de la estructura del Estado, teniendo en cuenta la actuación del principio de subsidiariedad, ba conllevado una modificación en la estructura burocrática pública, impactando en las relaciones de los ámbitos público y privado y de sus derechos correspondientes, pero no en la esencia del Estado.

Siguiendo a Parada (2007, p. 12), diremos que "en todas las civilizaciones se han producido fenómenos burocráticos, es decir, la organización de conjuntos de personas al servicio de los poderes públicos, monarquías o repúblicas, democracias o dictaduras, así como de las iglesias que han dominado a lo largo de la historia". El autor citado ubica su nacimiento a principios del siglo XIX con el surgimiento de los regímenes constitucionales, época en la cual no existían todavía las burocracias empresariales provenientes del devenir del capitalismo.

En el mismo sentido sostiene Panebianco que las burocracias públicas son el principal instrumento mediante el cual en Europa Continental se forma el Estado moderno. Mas aún, "el nacimiento y expansión de los aparatos administrativos son parte de un proceso más general de centralización-concentración del poder mediante el cual el Estado se afirma sobre las cenizas de la sociedad medieval" (Panebianco, 1996, p. 375).

En Francia fue una imposición autoritaria por parte de Napoleón. En los Estados anglosajones se implantó frente a la resistencia del pensamiento liberal.

Según la argumentación de Parada, "los ideólogos liberales estaban en contra del incipiente sistema burocrático ya existente en el siglo XVIII, que a su modo de ver, se había introducido un tanto clandestinamente y contradecía las esencias históricas y constitucionales británicas. Este pensamiento entiende que desde la perspectiva laboral, la Administración y la Burocracia son un mal en sí mismas. A esta tendencia anglosajona de corte liberal, se contrapone la corriente burocrática prusiana, la cual implica la aceptación -y no el combatede una burocracia, y la fe absoluta de que es el mejor modo de gobierno. Afirma el autor citado que Prusia le dejó a la civilización europea una forma política denominada "Estado de Funcionarios". En Estados Unidos, en cambio, debido a la correspondencia entre democracia y liberalismo económico, se rechaza la idea de un funcionariado inamovible. En este sentido, afirma Parada (2003, p. 382) que podemos diferenciar, como sistemas de función pública, los sistemas abiertos, como el norteamericano, y los sistemas cerrados, como el francés.

En el presente, tanto en América como en Europa, aconseja Comadira (2003, pp. 31-55) abordar investigaciones de los modelos de función pública comparada, más aun en aquellos países donde las recurrentes crisis sociales 
y económicas, generadas por situaciones de injusticia social no resueltas, requieren de un Estado eficaz y eficiente, para poder atender con inmediatez a las exigencias de bien común como causa final del Estado. Ello es aún más urgente cuando, con motivo de los grandes cambios operados en las últimas décadas, se ha comenzado nuevamente a requerir la jerarquización de los servidores públicos, la necesaria profesionalización de sus agentes para lograr un mejor Estado. Así, de acuerdo a la Carta Iberoamericana de la Función Pública, siendo el Estado la máxima articulación de relaciones sociales, su papel es fundamental para el logro creciente de bienestar colectivo ${ }^{2}$.

Panebianco (1996, p. 382) puntea una serie de dimensiones a la hora de realizar un análisis tipológico de las burocracias occidentales. La clasificación más general define dos grandes tipos, ya sea que se considere los sistemas burocráticos en su conjunto o solo las élites burocráticas. Los primeros pueden ser federales o unitarios. Mientras que en el tipo federal hay generalmente escasa intervención en la periferia, como es el caso de Estados Unidos o Alemania Occidental, en la que solo la mitad del empleo público se ubica en la administración central. En el tipo unitario se administra la periferia desde el centro. Tal es el caso de Francia, en la que la mayoría del empleo público está agrupado en el centro. También corresponden a esta tipología Gran Bretaña e Italia. El caso de Gran Bretaña representa una posición media entre ambas tipologías debido a su tradición de autogobierno y autonomía administrativa.

En el segundo caso se tiene en cuenta el tipo de división de trabajo, ya sea que se realice sobre bases funcionales, geográficas, tipos de clientes o de prestaciones burocráticas. Según el autor citado es posible, mediante la clasificación de estos criterios, llegar a tipologías complejas para la realización de análisis comparativos.

En referencia a los modelos de carrera, cuentan con criterios de ascenso y mérito, ascensos automáticos o concursos internos, siendo las posibilidades extremas las de una movilidad cero o la amplia como polo opuesto. El autor cita a Italia y Gran Bretaña respectivamente.

En cuanto al criterio del grado de permeabilidad o impermeabilidad, se considera un cuerpo cerrado a aquel que no tiene intercambios con las demás élites organizativas, políticas y sociales. Es cerrado en su entrada y en su salida, es decir que no hay ingresos laterales, correspondiendo a esta tipología la Italia republicana prefascista y Gran Bretaña. El segundo tipo sería el de cierre en su entrada pero no en su salida. Así, la alta burocracia proporciona sus cuadros a la clase política y a las estructuras directivas de las empresas privadas, como en

2 Conforme la Carta Iberoamericana de la Función Pública de junio de 2003, contempla dentro de sus objetivos definir las bases para un sistema profesional y eficaz de función pública ${ }_{i}$ configurar un marco genérico de principios rectores, políticas y mecanismos de gestión como lenguaje común para la comunidad iberoamericana; y servir de fuente de inspiración para la mejora y modernización de los sistemas nacionales de función pública. 
Francia y Alemania. El tercer caso corresponde a la abertura tanto de entrada como de salida. En este se dan cambios continuos en el sistema burocrático. A él se asemeja Estados Unidos.

El último criterio de clasificación que aporta Panebianco es el de generalidad o especialización, situándose su tipología en una posición intermedia entre dos extremos. El generalista en sentido impropio es el funcionario con formación jurídica, mientras que en sentido estricto es el funcionario con formación cultural genérica. El especialista es el que hace hincapié en formación administrativa específica. De todos modos se considera esta clasificación muy ambigua, porque el grado de educación no basta como criterio de diferenciación.

Los sistemas burocráticos públicos precitados se corresponden con la etapa del Estado liberal. La transformación de los mismos se desarrolla con la intervención del Estado. Dos aspectos son significativos para nuestro análisis. Por un lado, en el Estado de tipo intervencionista se acrecienta el empleo público, convirtiéndose en una cuota de expansión del gasto estatal, y, por otra parte, la intervención masiva del Estado en los procesos socio económicos ha favorecido un incremento del asociacionismo privado con finalidades de presión sobre el Estado.

Asimismo la sindicalización del empleo público en la época de masas implica la introducción de la contratación colectiva y, con ella, la relajación de la disciplina burocrática, la pérdida de la fuerza de los mecanismos jerárquicos como reguladores de la actividad administrativa, y la pérdida de la impronta jerárquico-autoritaria típica de las burocracias clásicas.

Las transformaciones acaecidas implican el pasaje de burocracias públicas dedicadas a programas condicionales, a crecientes programas de fines en los que el resultado es más importante que la conformidad a las disposiciones de la ley. En esta línea, la burocracia se ve implicada en relaciones con grupos y asociaciones externas en las que asume un papel de mediación.

En opinión de Rosanvallon, "El proyecto de erigir la administración a la categoría de poder dotado de un cierto margen de autonomía fue formulado al llegar el siglo XX. El simple hecho de pensar en esos términos producía una ruptura mayor con todos los enfoques anteriores de la política democrática [...] El poder surgido de las urnas, debía imponer sin restricción cada una de sus decisiones, y la administración era concebida como su pura prolongación" (Rosanvallon, 2009, p. 65). Este estado de cosas lo ilustran Estados Unidos y Francia, países en los cuales se da primariamente el afianzamiento del sufragio universal.

En el caso de Estados Unidos, la instauración del sistema de despojos o spoil system ${ }^{3}$ hacía del partido en el poder el casi propietario de los empleados

3 Se le atribuye a WiLliam MARCY -en un debate en el Senado- la frase "No hay nada de malo en la regla de que al vencedor le corresponden los despojos (spoils) del enemigo". 
públicos. Esta es una característica de los sistemas llamados abiertos que se fundan, como las empresas privadas, en un inventario muy preciso de los puestos de trabajo. El reclutamiento se hace para un puesto de trabajo concreto, no se entra en un cuerpo, ni se tiene derecho a una carrera o a ocupar otros puestos superiores.

En 1883 se crea la Civil Service Commission, estableciendo como sistema de designación de los funcionarios la selección con base en un sistema de méritos. Para ello se dispuso un examen de admisión y la supervisión de sus tareas. Asimismo consideraba ilegal el despido de empleados por razones políticas.

En cambio en Francia, país al que corresponde el sistema cerrado de carrera o sistema de función pública propiamente dicho, se partía de la base de que el servicio en la Administración Pública requiere una formación diferenciada y más completa, siendo necesario crear una disciplina y una moral de servicio. Elementos fundamentales de este sistema son el estatuto, el cuerpo y la carrera.

En la actualidad, si bien la elección histórica puede haber partido de un sistema cerrado, numerosos países en Europa han encarado reformas en las últimas décadas para orientarse cada vez más a un sistema de tipo norteamericano. Ese fue el caso de España con las reformas de 1964 y 1984. Así estos sistemas, que predominantemente se regían por un sistema de función pública, junto al cual vienen incorporando normas que permiten personal bajo un régimen laboral, generan inevitables tensiones y conflictos, como viene aconteciendo en España y Alemania (Parada, 2003, p. 388). En tales países se encuentra personal regido por el derecho privado de locación de servicios y de obra, incluso de consultoría, más cercano a un sistema de tipo estadounidense pero, siendo empleo público, goza de los beneficios tradicionales de tipo continental europeo, como lo son la estabilidad, el derecho a la carrera y el progreso en la misma.

Las instituciones en Francia dejan de ser vistas como encarnación de la voluntad popular. La subordinación de la administración al poder político pierde su fuerza original. Un proceso similar se produciría en países como Estados Unidos a principios de 1900. Allí los partidos políticos son vistos como responsables del clientelismo. Posteriormente las distintas teorías trabajan sobre los aspectos de la corrupción y la incompetencia, como elementos que deben ser superados en la administración.

Si bien América Latina siguió este último ejemplo, a partir de las reformas del Estado adopta un modelo abierto en el que se organiza como una empresa privada, en tanto que se incorpora al agente a un puesto de trabajo específico. Estos cambios han tenido una profunda incidencia sobre la organización jurídica y administrativa y, en consecuencia, sobre el empleo público. Un Estado, basado en el principio de subsidiariedad, condujo al desarrollo de la iniciativa privada, implementando los gobiernos diversas medidas de desregulación, tales como los procesos de transferencia de empresas y bienes del Estado hacia los particulares, privatizando importantes sectores de la actividad estatal. 
La problemática medular concierne a la legitimidad o a la inexistencia de la distinción público-privado. Su abordaje implica tres posturas: se enfatizan las diferencias, se cala en las semejanzas o se apuesta a la convergencia.

Desde la perspectiva estrictamente jurídica, Cassagne afirma que la evolución comparatista revela el desarrollo de una compleja trama de relaciones entre las citadas instancias, caracterizadas por la interpolación que sucesivamente se ha ido operando entre ambas ramas del derecho.

Siempre delineado por cuestiones coyunturales, provenientes de la economía, la sociedad y la tecnología, entre otras, sostiene el jurista que las mismas han desplazado la influencia de concepciones ideológicas, en un acelerado proceso que ha pasado por diferentes etapas. Dice: "De una huida inicial del Derecho Administrativo (coincidente con el fin del ciclo del Estado benefactor) se pasó a una extensión de su contenido a través de un proceso de interpolación entre lo público y lo privado. Esta interpolación no implica, necesariamente, unificar los derechos -como ocurre actualmente en Europa- sino sentar una serie de reglas comunes aplicables en el marco del derecho comunitario que, como es sabido, se proyecta al Derecho interno de cada Estado" (Cassagne, 2003, p. 86).

También la doctrina española, en la que se inscribe Rivero Ortega, nos recuerda respecto de las transformaciones del Estado, en orden a los cambios sociales, políticos y económicos, su necesaria incidencia sobre la organización administrativa. Sostiene que dichas transformaciones corresponden a la etapa del Estado intervencionista, dando lugar a una huida del Estado (Rivero Ortega, 1998, pp. 18-19).

En esta línea argumental, Rivero Ortega entiende que la aparición tanto de nuevas necesidades de los ciudadanos como de la asunción de nuevos roles del Estado concluye en una hipertrofia del derecho público. Esta convergencia de factores -indica el autor- lleva a la administración a desprenderse de sus ataduras y, de esta manera, eludir complejas regulaciones jurídicas.

Señala asimismo que la "huida al Derecho privado" toma forma bajo una estructura organizativa de la administración y que, al elegir una forma organizativa sujeta al derecho privado, implica tomar como punto de partida un abandono del derecho público.

Desde el punto de vista económico, sostiene Rivero Ortega (2001, p. 33) que la privatización, tanto como la liberalización, la desregulación y la globalización, obliga a un replanteo de las técnicas de intervención en la economía.

En este sentido, el fuerte protagonismo del Estado cede su espacio a la empresa privada para la satisfacción de las necesidades de la comunidad, implicando una crisis financiera del Estado, el cual se ve como fuente de corrupción, clientelismo e intervencionismo sindical, que no se adapta al mercado $y$, por lo tanto, con falta de racionalidad en el gasto.

Con un criterio similar, Ramió Matas, al analizar la débil institucionalización de las instituciones públicas en América Latina, entiende que -en el 
marco de las transformaciones precitadas- se genera una problemática crítica respecto de la gobernabilidad, agravándose con la globalización comercial y la sociedad de la información (Ramió Matas, 2001, pp. 252 ss.).

En este orden de ideas y en coincidencia con el planteo de Rivero Ortega, otra doctrina europea, como la de García De Entrerría (2014, p. 391), señala que con la excusa de flexibilizar la acción administrativa se articula decididamente una huida del derecho público. Aporta este autor la idea del empleo de la técnica de creación de entes instrumentales. Basando su análisis en las transformaciones operadas en el Estado en la década de 1980 y principios de 1990 sostiene que las administraciones públicas de América Latina se hallaban en un proceso de transformación para conseguir instituciones que se acerquen al modelo weberiano, abriéndose estas administraciones a una novedosa gestión pública que relaja y flexibiliza procesos introduciendo valores empresariales. La conclusión del citado autor es que de este proceso no se sale fortalecido sino que se favorece el clientelismo y la inseguridad jurídica.

Observa la mencionada doctrina que a través de estas políticas se genera una administración relacional, lo que implica una ruptura de las clásicas formas de Administración pública que gestionaba históricamente los servicios, para dar paso a una internalización del control, la planificación y la decisión. En consecuencia, el resultado de estos cambios de paradigma fue la disminución de la calidad en los servicios públicos.

Siguiendo la línea europea, este proceso lo integran "entes instrumentales sujetos al derecho privado", doctrina que autores como Garrido Falla sostienen que, cuando se trata de entes públicos en cuyo régimen jurídico es el de derecho privado, el Estado debe incorporar normas propias del mismo (Garrido Falla, 1993, pp. 399 ss.). Esta temática no resulta novedosa para la doctrina española, que en algunos casos tiene precedentes desde la década de 1960, en las normas del área de ferrocarriles y transporte, entre otros, con las diferencias expuestas del modelo argentino.

De acuerdo a lo expresado, existe una tendencia por parte del Estado de satisfacer las nuevas demandas y necesidades de la comunidad a través de mecanismos más ágiles y eficientes, lo que necesariamente obligó a recurrir a normas del derecho privado para su gestión, pero, como ha podido observarse en esta apretada síntesis en relación a algunas doctrinas europeas, el desplazamiento del derecho público hacia el privado se plantea como un movimiento de adentro hacia afuera. En nuestro derecho transcurre de manera inversa. Entendemos que en los procesos de privatización (habiendo advertido la gran demanda de la comunidad y la ineficiencia del Estado) se ha definido un movimiento de carácter exógeno debido a la recepción de normas del derecho privado que se consideran externas al derecho público. Si relacionamos este planteamiento con la concepción del Estado como el ámbito en que se resuelve el "bien común" podemos colegir que, aun incorporando normas ajenas, el Estado conserva su esencia. 


\section{TERCER ARGUMENTO}

La mutación del bloque de legalidad referido al empleo público, debido a la incorporación de normas del derecho privado, es solidaria con el proceso de desnaturalización precitado.

La mutación del bloque de legalidad, que logra su máxima concreción en la década de 1990, tiene sus antecedentes en la normativa internacional y regional como consecuencia de la globalización antes mencionada. Comenzando por el ámbito internacional, varios convenios de la Organización Internacional del Trabajo (OIT), como organismo dependiente de la Organización de Naciones Unidas (ONU), dedicado a temas vinculados al trabajo en general, han implicado nuevas reglas de juego que impactaron en las normas de los países, en relación con el empleo público. Estos convenios se aplican en Argentina desde el momento en que se sancionaron las respectivas leyes nacionales que los ratificaron, algunos de ellos anteriores a la reforma de la Constitución del año 1994.

El Convenio n. ${ }^{\circ} 87$ de 1948, ratificado por la Ley 14.932/59, consagra la libertad sindical y la protección del derecho de sindicalización, el cual, junto con el derecho de negociación colectiva, es objeto del convenio n. ${ }^{\circ} 98$ de 1949 único ratificado por un gobierno de facto a través del Decreto Ley 11.594/56. El Convenio n. ${ }^{\circ} 151$ de 1978 -refrendado por la Ley 23.328/86- protege el derecho de sindicalización. Este acuerdo es de fundamental importancia en el tema que tratamos, dado que el mismo atañe a los procedimientos para determinar las condiciones de empleo en la Administración pública. El Convenio OIT n. ${ }^{\circ}$ 154, confirmado por la Ley 23.544/88, vuelve sobre la negociación colectiva.

Cronológicamente hablando y desde el ámbito geográfico global, el denominado "Consenso de Washington", acuñado en 1989 y conocido por la delimitación del marco económico-político, que establece medidas para la mayoría de los países de América Latina -entre otros-, tales como dejar de percibir nuevo financiamiento externo y quedar atados al sistema financiero internacional mediante la negociación de las respectivas deudas contraídas, impacta desfavorablemente sobre el trabajo en general, no siendo la excepción el empleo público. Las políticas posteriores intentaron subsanar los efectos no deseados por la aplicación de las medidas del consenso citado. Quince años más tarde, nuevamente en el ámbito regional, se dicta la Carta Iberoamericana de la Función Pública (en adelante CIFP) en Santa Cruz de la Sierra, Bolivia, la cual es aprobada en el contexto de la V Conferencia Iberoamericana de Ministros de Administración Pública y Reforma del Estado, siendo ratificada por la simultánea XIII Cumbre Iberoamericana de Jefes de Estado y de Gobierno (CLAD, 2003).

La CIFP se propuso definir las bases para un sistema profesional y eficaz de función pública y configurar un marco genérico de principios rectores, 
políticas y mecanismos de gestión como lenguaje común para la comunidad iberoamericana.

En el ámbito nacional, nuestra Carta Magna, desde su primera sanción, hasta la última reforma, ha incidido en las regulaciones del empleo público. Cabe destacar que la Constitución sancionada en 1949 y derogada en 1955 defiende, entre otros derechos, los del trabajador, constituyéndose en antecesora de aquella que la deroga y reemplaza. En efecto, el texto sancionado en 1957 defiende los derechos colectivos, principalmente de los trabajadores. El artículo 14 bis, incorporado a la Constitución Nacional histórica en la reforma constituyente de 1957, atenúa el espíritu liberal de los derechos, garantías y atribuciones del texto originario, condicionándolos a las nuevas normas de tinte "constitucional-social", algunas incluso de carácter operativo (p. ej., el derecho a la huelga). Finalmente, el texto resultante de la reforma constitucional llevada a cabo en 1994 recepta las normas supranacionales, lo que implica el cumplimiento de los derechos humanos en general y del trabajador en particular. Defiende asimismo los derechos medioambientales que impactan valiosamente en las condiciones laborales de los trabajadores.

En coherencia con la Carta Magna, la legislación nacional y las normas complementarias y convencionales naturalmente han mutado respecto de la problemática en cuestión.

La Ley 22140 sancionada en 1980 aprueba el Régimen Jurídico Básico de la Función Pública, que reemplaza al Decreto 6666/57.

Durante la primera década de vigencia se ha normado escasamente sobre la cuestión del empleo público, salvo los decretos 2098/87 y 957/1988 que crean el Cuerpo de Administradores Gubernamentales y la modalidad del retiro voluntario, respectivamente. A diferencia de dicha década, en la siguiente, correspondiente a los años 90, una mayor cantidad de normas transversalizaron la cuestión del empleo público, pero será recién en 1999 que la Ley 22.140 será derogada y sustituida por la Ley 25.164. Las políticas públicas aplicadas durante la década citada provocaron importantes consecuencias en la relación laboral que se origina en el contrato de empleo público.

Todo el proceso se realiza en el marco de dos leyes principales: la Ley de Reforma del Estado n. ${ }^{\circ}$ 23.696 y la Ley de Emergencia Económica n. 23.697.

A su vez, mediante el Decreto 1757/1990, de Racionalización del Gasto Público, se disponen normas esenciales referidas a la reforma administrativa. Este decreto crea en el ámbito del Ministerio de Economía el Comité Ejecutivo de Contralor de la Reforma Administrativa (CECRA).

Se dictó luego el Decreto 2476/90, referido a la racionalización de estructuras, plantas no permanentes, modernización tecnológica, jerarquización, reducciones complementarias de dotaciones, jubilaciones de privilegio, y otros.

El 27 de mayo de 1991 se crea el SINAPA (Sistema Nacional de Profesión Administrativa) por el Decreto 993, con el fin de reorganizar la eficiencia en el empleo público. El Decreto 1.545/94 hace referencia al congelamiento de 
vacantes. El 28 de diciembre de 1994 se sanciona la Ley de Presupuesto del año 1995 n. ${ }^{\circ} 24.447$, que establece la posibilidad de contratar los servicios de personal idóneo.

La segunda reforma del Estado es instrumentada mediante la Ley 24.629/1996. Para su concreción, se crea en el ámbito de la Jefatura de Gabinete de Ministros, por el Decreto 558/96, la Unidad de Reforma y Modernización del Estado (URME), eliminándose el CECRA ya citado.

Finalizando el período, se sanciona la Ley 24.185/1992, de Convenios Colectivos para Trabajadores del Estado. Posteriormente, por el Decreto 66/99 se homologa el Convenio Colectivo de Trabajo General para la Administración Pública Nacional, siendo reemplazado dicho decreto por el 214/06.

Finalmente, la Ley 25164, Ley Marco de Regulación de Empleo Público Nacional, surgió a modo de evolución de otras leyes y normas que hacían referencia a la misma cuestión. Dicha ley fija un marco legal por el cual se regirá la actividad del empleado público. Por su parte, el Decreto 1421/2002 reglamenta la última ley citada.

Si bien toda la normativa refrendada durante los años 90 instrumentó las cuestiones referidas al empleo público, lo hizo flexibilizándolo. Sus antecedentes preparan el escenario. En efecto, los derechos de sindicalización, libertad sindical y el fomento de la negociación colectiva suponen un encuadre facilitador para la flexibilización del empleo en términos del mejoramiento colectivo laboral, pero obsérvese que en el caso del empleo público deben establecerse condiciones especiales, debido al carácter de asimetría en la relación entre las partes del contrato.

Por su parte, el Consenso de Washington determina condiciones más definidas y orientadas hacia la flexibilización laboral. En esa línea, las normas aplican a Argentina, y si bien los diversos textos constitucionales inciden en la protección de los derechos del trabajador, no alcanzan para limitar los efectos.

\section{CUARTO ARGUMENTO}

Los procesos que la doctrina ba denominado de laboralización, flexibilización y precarización del empleo público explican las consecuencias de la incorporación de las normas del derecho privado en el ámbito del empleo público.

Retomando los planteos de los autores citados, respecto del proceso de laboralización $_{i}$ de la sociedad de la particularidad ${ }_{i}$ del turbo capitalismo; de la huida del derecho público al derecho privado; del proceso de interpolación entre lo público y lo privado por un lado, y las modificaciones operadas en el bloque de legalidad por otro, indefectible resulta para el derecho administrativo plantearse si la flexibilidad de la protección de los derechos del empleado o funcionario se entiende en un sentido favorable o disvalioso para el empleado 
regido por el derecho privado, para luego ver de qué modo se introduce en el ámbito público.

En el derecho privado, para algunas doctrinas, como la de Ermida Uriarte (2003, p. 134), al analizar la postura de Javillier, se considera que el derecho del trabajo siempre tuvo una flexibilidad "hacia arriba", es decir, que el derecho laboral ha dictado normas de carácter tuitivo para el trabajador. Sin embargo, este autor señala que hoy en día el concepto de flexibilidad en el derecho del trabajador posee un efecto disvalioso para el trabajador (hacia abajo).

Aduce con gran acierto Ermida Uriarte que en muchos países latinoamericanos se reclama la flexibilización jurídica o normativa sin contrapartida. Argentina ha tenido antecedentes de flexibilización normativa en la que, con el criterio de sostener la fuente laboral, se han resignado derechos de los trabajadores, aunque es justo decir que no ha sido siempre este el criterio. Lo que nos plantea la doctrina para estos supuestos es que. como sucede en países europeos, la contrapartida, ausente en este caso, debería ser previa, como por ejemplo desarrollos productivos, inversiones, nuevas tecnologías, etc. (Ermida Uriarte, 2003, p. 38). Concluye en consecuencia que los presupuestos de la flexibilización son tanto económicos como tecnológicos-productivos.

Los fenómenos de laboralización y flexibilización provocan la precariedad del empleo en nuestro país. Por otra parte, teniendo en cuenta lo tratado respecto de la cuestión de derecho público-derecho privado, recordamos que la acción política ha requerido en la década de 1990 una asociación públicaprivada donde el otro es reconocido como socio. En consecuencia, el derecho administrativo ha ido adecuándose a esta coyuntura. En este orden es que el derecho público ha incorporado normas del derecho privado o, como sostienen otras doctrinas, el derecho público ha huido al derecho privado.

La secuencia parece ser la siguiente: transformación del Estado, reforma del Estado, desregulación del derecho público, flexibilización del empleo público, recurrencia al derecho privado o laboralización. Esta última se comprende en una doble dirección, ya sea que se incorpore lo privado en lo público o que lo público huya hacia lo privado. Lo cierto es que el Estado terceriza, agencializa, etc. Es decir, incorpora o recurre a terceros sin perder su status quo.

Para entender la trascendencia de este planteamiento, pensemos que el Estado posee las atribuciones denominadas "potestades exorbitantes", que implican que tiene atribuciones que aplicadas en el derecho privado serían irregulares. Esa potestad tiene que ver con el fin del Estado en relación con la preservación del bien común.

Uno de los efectos fundamentales de los procesos mencionados es la precarización. En este sentido, el término precario adjetiva al empleo, es decir que el empleo precario significa tanto la disminución de la calidad del servicio que presta un agente o funcionario público como la calidad de la vida del mismo. Pero, fundamentalmente la precariedad hace referencia a la pérdida, no solo de la calidad, sino también de la naturaleza de una de las partes del contrato 
en el caso del empleo público. En efecto, esto es así porque no es una relación de paridad sino que es asimétrica.

A lo largo del tiempo se ha llegado a definir al empleo precario de muchas y variadas formas. En particular, ello se debe a que su significado no es igual en cada ámbito de trabajo, ya sea que se trate dentro del sector público o el privado.

En la búsqueda de definiciones genéricas del término, varios autores coinciden en que el mismo representa todo aquel trabajo que no está registrado y se lleva delante de manera ilegal y clandestinamente (Alvater, 2008)

En Argentina gran parte del empleo se halla bajo estas condiciones, verificándose dicha afirmación en las reiteradas y periódicas averiguaciones que efectúa el INDEC mediante su encuesta permanente de hogares, en donde a las personas se les pregunta si trabajan, y frente a la respuesta afirmativa, responden que no se les realiza aporte alguno por dicha actividad. Por lo general, el trabajo precario se encuentra dentro de la órbita privada.

El trabajo precario, a la vez, no solo se caracteriza por su ilegalidad, sino por las condiciones generales bajo las cuales se desarrolla. En diferentes informes realizados por la OMS (Organización Mundial de la Salud) se verificó que en gran cantidad de países de Latinoamérica el empleo informal no solo es precario respecto a su formalidad y legalidad, sino que muestra claras deficiencias en el ámbito de la salud y las ondiciones dignas de trabajo para el ser humano (OMS, 2002).

Una de las consecuencias del empleo precario es el surgimiento de un sector social muy débil debido a la falta de seguridad laboral. Lo relativo a la situación laboral por la que atraviesa un país no es un aspecto aislado. Debido a ello es que se debe tener presente el contexto bajo el cual se desarrolla el empleo. Tratándose del empleo público, ello es más elocuente aún en un país con condiciones particulares como lo es Argentina. Dentro del contexto citado podemos afirmar que las consecuencias del empleo precario se extienden al ámbito de la cultura del trabajo y a la predisposición al mismo, las políticas de empleo, las políticas de desempleo, la formalidad del trabajo, el desarrollo de la economía en el largo plazo y los ámbitos político, social y educativo.

En tal contexto ideológico, Bastons (2006, pp. 15-55) plantea que la reforma del Estado pasó principalmente por la venta de todo tipo de activos estatales, la privatización de la inmensa mayoría de los servicios públicos y la expulsión de empleo público por medio de retiros voluntarios y jubilaciones anticipadas. Se instauró una suerte de laboralización negativa del empleo público que refiere a que no solo las contrataciones de personal en el sector público se volcaron mayormente hacia regímenes de derecho privado, sino que el empleo público tradicional (léase, el derecho público con estabilidad plena) se vio jaqueado por acciones tendientes a su exterminio. Para Menéndez (2009, p. 122), la precariedad se refiere al incremento de la vulnerabilidad de los trabajadores tanto en la estabilidad como en la calidad de las condiciones de trabajo. Así, esta precarización como proceso comporta la creciente utilización del régimen 
de contratos, o de seudo contratos, como señala García Pulles (2005, p. 35), por medio de locaciones de servicios o de obra, al amparo del artículo 47 de la Ley Complementaria Permanente de Presupuesto 11.672/99, reglamentada por el Decreto 1184/01, que sustituyó su similar anterior 92/95, aplicable a las locaciones de servicios, y los decretos 1023/01 y 436/00 para las locaciones de obra, ${ }_{i}$ a las numerosas contrataciones con fondos extra presupuestarios provenientes de entes cooperadores.

El personal de trabajo, bajo estas condiciones, desarrolla muchas veces tareas propias del personal permanente del Estado, es capacitado y se prorrogan sus contratos sucesivamente, siendo descartado al finalizar la gestión y reemplazado por nuevos contratados del nuevo gobierno, recomenzando el proceso de capacitación.

Comadira (2003, pp. 31-55) señala que esto constituye otra fisura en la estabilidad constitucional: "si se toma en cuenta que la estabilidad, como requisito para la carrera administrativa y la consecuente profesionalización, cede ante la precariedad laboral propia del régimen privado en ámbitos importantes de la organización estatal, es posible concluir que al menos en este aspecto, la profesionalización de la función pública en nuestro país está seriamente afectada".

Son numerosas y disímiles las soluciones jurisprudenciales para los reclamos de los afectados frente a la conclusión intempestiva de tales contrataciones, en algunos casos ante sus continuas prórrogas alegaron la estabilidad del empleo público, o su derecho a ser considerado de planta permanente, o aduciendo una relación de contrato laboral privado, reclamando la indemnización correspondiente del artículo 275 y demás beneficios de la Ley de Contrato de Trabajo.

El marco legal actual contempla hoy las dos posibilidades de contratación. De acuerdo con Menéndez (2009, pp. 123-125), "los de planta permanente (agente públicos cabalmente) y los contratados en virtud del Decreto 1421/2002 [son] quienes constituyen una planta de trabajadores con características híbridas dado que poseen casi todas las mismas prerrogativas que la planta permanente, con excepción de la estabilidad, ya que son contratos con plazo de vencimiento máximo de un año. Es de destacar que el régimen contemplado en el Decreto 1421/2000 comenzó a hacerse efectivo de modo significativo entre 2005 y 2006". Frente a esta coyuntura, la autora citada afirma que si bien no se cuenta con información previa al año 2001, "es altamente presumible que los contratos cumplieron -desde su implementación (masiva) en los albores de la década del noventa- un rol sustancial, en la medida en que se constituyeron en la modalidad prácticamente exclusiva de ingreso al sector público" (Menéndez, 2009, p. 125). Entre las dimensiones relativas a la precariedad son señaladas la falta de estabilidad del empleo público, el deterioro de las condiciones de trabajo, incertidumbre e insuficiencia del ingreso, la reducción de la protección y seguridad social, el deterioro en el reconocimiento práctico y simbólico de la realidad del trabajo, la inestabilidad política del vínculo contractual y la falta de representación y cobertura sindical. 
Como dice Bastons (2006, p. 22), "la confusa maraña conceptual que hoy opera en torno del empleo público, era hace treinta o cuarenta años un escenario tan claro como para invitarnos a recordar con melancolía que, por aquel entonces, el Derecho y la realidad eran lo suficientemente coincidentes como para mantener en pie la diferenciada conceptualización doctrinaria acerca de lo que era (y lo que no) el empleo público".

\section{CONSIDERACIONES FINALES}

La contextualización histórica del Estado ha permitido visualizar que, como ente real, el mismo tiene su finalidad natural en el bien común. Pero ha sido a partir de las transformaciones de dicha estructura que el Estado subsidiario cuenta con dos elementos esenciales: la recurrencia al mercado y la posibilidad de la intervención de terceros en la relación Estado-comunidad. Así, la contemplación de la acción de organizaciones intermedias que puedan suplir las acciones del Estado posibilita la conformación de un sindicato como órgano capaz de intervenir en el ámbito laboral.

La reforma del Estado, a partir de estas transformaciones, conlleva la tecnocracia que facilita tanto la acción como los efectos de la desregulación, la cual deviene en un proceso de laboralización debido a la cuestionada relación público-privado. El Estado realiza su acción -en aras del bien común-a través de la Administración Pública, pero el mismo pierde su naturaleza, toda vez que actúe simétricamente en la relación bilateral del contrato de empleo público. Es preciso establecer por lo tanto los límites dentro de los cuales se desenvuelve el contrato administrativo de empleo público.

En primer lugar, la naturaleza refiere a una relación jurídica de derecho administrativo, ajena a la locación de servicios y al ámbito del contrato de trabajo (LCT 20.744), en la cual el Estado procede como Poder Público. Esta distinción que se va configurando en la jurisprudencia de la CSJN no ha sido modificada a la fecha.

Por otra parte, la relación precitada es, para la doctrina mayoritaria, de índole contractual aun cuando existan normas reglamentarias o estatutarias que la regulan (históricamente, Decreto-ley 6666/57, Ley 22.140, Ley 25.164) como marcos generales, sin perjuicio de los diversos estatutos especiales en diferentes ámbitos.

Se advierte que, con motivo de la "laboralización" de las relaciones de empleo público y el dictado de la Ley 24.185 y la suscripción de convenios colectivos públicos de empleo público -no comprendidos en la Ley 14.250-, se ha producido un cambio significativo en la regulación de empleo de esta naturaleza.

Se puede discurrir a este respecto que se ha pasado de una vieja relación contractual pero estatutaria, en la que el Estado fijaba por sí mismo el con- 
tenido de la relación de empleo, a una relación contractual y convencional colectiva de derecho público, con lo cual el contrato administrativo de este tipo de empleo se integra.

A partir de 1983, con el retorno de la democracia y la ratificación de convenios OIT, se avanza más en las consideraciones tuitivas de los derechos de todos los trabajadores, incluido el personal que se desempeña en el ámbito público, reforzado ello por la modificación constitucional de 1994 y por el rango constitucional otorgado a los tratados internacionales.

En este contexto se acelera en la década de 1990 el criterio de transferir al régimen laboral privado a multiplicidad de agentes públicos, de diferentes actividades. También se crean organismos -entes reguladores de servicios públicos (Ente Nacional Regulador de la Electricidad, ENRE, Ente Nacional Regulador del Gas, ENERGAS, etc.- cuyo personal, por ley o por decreto, se incorpora al régimen de la LCT.

Durante la década de 1990, en el marco del proceso de reforma del Estado, se produce un fenómeno -concomitante a los citados- que algunos autores denominan "precarización", en particular en oportunidad de la llamada Segunda Reforma del Estado, y en el avance de los procesos de racionalización administrativa y el consecuente congelamiento de las vacantes, para cubrir las plantas permanentes en 1994.

Si bien el Estado se encuentra facultado para realizar contrataciones de locaciones de servicios y de obra, que no son contrato de empleo público, y que tampoco caen dentro de las normas del derecho laboral privado, lo cierto es que en la década de 1990 se instrumenta un mecanismo de "contratación" vía el artículo 47 de la Ley Complementaria Permanente de Presupuesto 11.672/99 y sus decretos reglamentarios -sistema que continúa hasta la actualidad-, el cual es utilizado abusivamente con desvío de poder por parte del Estado, junto con otros mecanismos como el recurrir a contrataciones tercerizadas, vía organismos internacionales, entes cooperadores, etc.

Una verdadera "tecnocracia paralela" sirve para incorporar personal de modo precario. Muchos de sus empleados trabajan en una sede administrativa del Estado, pero cobrando un salario distinto del resto de los trabajadores estatales. La Ley 22.140 incorporó previsiones con la posibilidad de designar "plantas transitorias de personal". Conforme criterios reiterados de la CSJN, no obsta a ello que los agentes realicen las mismas tareas que el personal de planta, siendo la característica esencial su carácter transitorio. También señaló que el mero transcurso del tiempo no modifica la condición de este tipo de contratos. Estos contratados, aun siendo empleados públicos, carecían de estabilidad. En este contexto, la Ley 24.185 debería ser objeto de reflexión, respecto de los límites que caben respetarse en las convenciones colectivas. Las convenciones colectivas refuerzan el proceso de laboralización del empleo público una vez dictada la Ley 24.185. 
Se puede afirmar que el proceso que denominamos de desnaturalización se acentúa cuando, por el mecanismo de la convención colectiva -en virtud del principio de subsidiariedad-, los sindicatos intervienen en el establecimiento de las condiciones de la función y la remuneración del personal. El Estado modifica su carácter de poder público cuando negocia como empleador con los sindicatos, verificándose una autolimitación de sus cláusulas exorbitantes, incluso en su rol de empleador, donde resta evaluar el costo para la eficacia y eficiencia de la administración.

Si se sigue el hilo lógico de las argumentaciones explicitadas en este artículo, se puede deducir que la utilización de normas del derecho privado no implica una huida del derecho público, como sostienen las doctrinas europeas. Por otra parte, el movimiento de carácter exógeno precitado no modifica la esencia del Estado. Es decir que la doctrina describe y define sucesos que es preciso profundizar y analizar desde variadas aristas implicadas.

En este sentido, es lícito afirmar que la introducción de normas (movimiento exógeno) que definimos "más próximas al Derecho privado", una vez introducidas en la órbita del derecho público, experimentan una adaptación que no impacta forzosamente en la mutación de ese derecho.

En otras palabras, el derecho público representa la matriz desde la cual las normas más próximas al derecho privado deben ser interpretadas y aplicadas conforme a sus principios y criterios.

Se puede colegir, en ese hilo argumental, que la hipótesis de la "desnaturalización" permite comprender un fenómeno de carácter holístico, desde esa misma perspectiva.

Los procesos manifiestos en la realidad desde los años ya citados evidencian una profunda contradicción toda vez que el Estado actúe como parte igualitaria de un contrato de empleo público, y toda vez que se interpreten las normas como mutantes per se. Cabe, en consecuencia, dar continuidad a estos planteamientos y estudiar los efectos de tales contradicciones en el mundo empírico.

La hipótesis de la desnaturalización, por lo tanto, permite comprender este entramado del Estado, abarcando de este modo un complejo fenómeno de causas y efectos que provocan nuevos efectos sobre el bien común, el servicio público y la situación de los agentes.

\section{BIBLIOGRAFÍA}

AltVater, E. (2008). La globalización de la inseguridad. Trabajo en negro, dinero sucio y política informal. Buenos Aires: Editorial Planeta.

ARIAS, F. L. (2006). Algunas reflexiones en torno a la naturaleza jurídica de la relación de empleo público, pp. 63-82. En J. L. BASTOns, Empleo público. La Plata: Librería Editora Platense. 
Aristóteles. (1994). Ética Nicomaquea y Política. México: Porrúa.

Barra, C. R. (2006). Tratado de derecho administrativo. Buenos Aires: Editorial Abaco de Rodolfo Depalma, tt. 2 y 3.

BASTONS, J. L. (2006). Las nuevas coordenadas del empleo en el sector público, pp. 15-55. En J. L. BAstons, Empleo público. La Plata: Librería Editora Platense.

Ben Plotkin, M. y E. Zimmermann (2012). Las prácticas del Estado. Política, sociedad y elites estatales en la Argentina del siglo XX. Buenos Aires: Edhasa.

Bidart Campos, G. J. (2006). Tratado elemental de Derecho Constitucional Argentino. Buenos Aires: EDIAR, t. 1-B.

BielsA, R. (1964). Los agentes de la Administración Pública. Funcionarios y empleados. El Dominio Público. En Derecho Administrativo. Buenos Aires: La Ley. 6. a ed., t. III.

Bielsa, R. (1960). La Función Pública. Caracteres jurídicos y políticos. La moralidad administrativa. Buenos Aires: Roque Depalma Editor.

Botassi, C. (2006). Ensayos de Derecho Administrativo. Buenos Aires: Librería Editora Platense.

Cagnoli, C. R (2003). Reflexiones sobre las reformas de Estado y de la Administración Pública de los ‘90 en Argentina. Ponencia del segundo Congreso Argentino de Administración Pública, Córdoba, Argentina.

Capon Fila, R. E. (2006). Apuntes sobre algunos temas pendientes en el empleo público: sindicalización de las fuerzas armadas y de las fuerzas de seguridad; tramitación de reclamos ante la justica del trabajo. En J. L. BASTONS, Empleo público. La Plata: Librería Editora Platense.

Carnota, W. (2013). Teoría Constitucional. Buenos Aires: Editorial La ley.

Carta Iberoamericana de la Función Pública. Aprobada por la Quinta Conferencia Iberoamericana de Ministros de Administración Pública y Reforma del Estado, Santa Cruz de la Sierra, Bolivia, 26-27 de junio de 2003, Respaldada por la XIII Cumbre Iberoamericana de Jefes de Estado y de Gobierno (Resolución n. ${ }^{\circ} 11$ de la "Declaración de Santa Cruz de la Sierra"), Bolivia, 14-15 de noviembre de 2003.

Cassagne, J. C. (2013). La regulación legal del contrato de empleo público. La Ley. Año 74, n. ${ }^{\circ} 182$, pp. 1-3.

Cassagne, J. C. (1993). La buelga en los servicios públicos. Madrid: Civitas.

Cassagne, J. C. (2003). Derecho Administrativo. Buenos Aires, Lexis Nexis AbeledoPerrot. 7. ${ }^{\text {e ed., t. I. }}$ 
Cassese, S. (2003). La crisis del Estado. Buenos Aires: Abeledo-Perrot.

Centro Latinoamericano de Administración para el Desarrollo. Clad.org [En línea] Carta Iberoamericana de la Función Pública. [Citada el 20-08-2013]. Acceso y disponibilidad en: <http://www.clad.org/documentos/declaraciones/cartaibero. pdf/view>

Colección de Anales de Legislación Argentina, tomo correspondiente a las normas publicadas en el año 1950.

Comadira, J. R. (2003). La profesionalización de la administración pública. En Temas de derecho administrativo, en honor al Prof. Doctor Agustín Gordillo, pp. 31-55. La Plata: Librería Editora Platense.

Contrera, G. (2007). Derecho Laboral y Provisional. Buenos Aires: Universidad Nacional de la Matanza.

Cordone, H. (1999). Consideraciones acerca de la evolución de las relaciones laborales en la historia argentina reciente (1955-1983). En ARTURO A. FERNÁNDEZ y RAúl H. Bisıo (comps.), Política y relaciones laborales en la transición democrática argentina. Buenos Aires: Lumen/Humanitas.

De La Fuente, H. (2001). La privatización del empleo público. Buenos Aires: La Ley. T. B.

Devealy, M. (1983). El Derecho del Trabajo en su aplicación y sus tendencias. Buenos Aires: Astrea.

Di Tella, T. S. (y otros) (2001). Diccionario de Ciencias Sociales y Políticas. Buenos Aires: MC Editores.

Diana MenÉndeZ, N. (2010). La múltiple dimensión de la precariedad laboral: El caso de la Administración Pública en Argentina. Revista de Ciencias Sociales, Costa Rica, 128-129, pp. 119-136.

Dromi, R. y Menen, E. (1994). La Constitución reformada. Comentada, interpretada y concordada. Buenos Aires: Ediciones Ciudad Argentina.

Dromi, R. (2006). Derecho Administrativo. Buenos Aires: Ediciones Ciudad Argentina.

Dromi, R. (1997). Empresas públicas: de estatales a privadas. Buenos Aires: Ediciones Ciudad Argentina.

ERlim, J. (2010). Las contrataciones del personal por parte de la Administración Pública con sustento en regímenes especiales a la luz de dos recientes fallos de Corte. Humo sobre el agua. Revista de Derecho Administrativo, Abeledo Perrot, n. ${ }^{\circ}$ 73 , septiembre. 
ERMida URIARTE Ó. (2003). La flexibilidad laboral: perspectiva latinoamericana en González Delgado. Responsa Iurisperitorum Digesta, vol. v. España: Ediciones Universidad Salamanca.

Fernández Madrid, J.C. (1989). Tratado Práctico del Derecho del Trabajo. Buenos Aires: La Ley.

García de Enterría, E. (2000). Curso de Derecho Administrativo, vol. 1. Madrid, Civitas, séptima ed.

García Pulles, F. (2005). Rédimen de Empleo Público en la Administración Nacional. Ley Marco de Regulación de Empleo Público Nacional aprobado por la Ley 25.164 y Reglamentación aprobada por Decreto 1421/2002, comentado y anotados con remisión al Convenio Colectivo de Trabajo General Homologado por Decreto 66/1999. Buenos Aires: Lexis Nexis.

Garrido Falla, F. (1993). Un tema de seguridad jurídica, la regulación de los entes instrumentales. Rueda n. ${ }^{\circ} 79$, pp. 399 ss.

GonzÁlez Delgado, J. Á. (ed.) (2003). Responsa Iurisperitorum Digesta, vol. v. España: Universidad Salamanca.

Gordillo, A. (2003). Tratado de Derecho Administrativo, t. I, Parte General. 8. a ed. Buenos Aires: Fundación de Derecho Administrativo.

HutChinson T. (2004). Breves reflexiones acerca de la función pública. Revista de Derecho Laboral II. Santa Fe: Rubinzal-Culzoni, pp. 36-37.

IldarRaZ, B. (y otros) (1999). Derecho Constitucional y Administrativo. Córdoba: Eudecor.

INAP - Reseña del proceso de reforma del Estado en la Argentina (1989-1996), Serie I, Desarrollo institucional y reforma del Estado, Doc. n. ${ }^{\circ}$ 58, Argentina.

IvaneGa, M. M. (2012). Comentario al Fallo Silva Tamayo. Revista de Derecho Administrativo n. ${ }^{\circ}$, abril. Abeledo Perrot.

IVANEGA, M. M. (2009). Las relaciones de empleo público. Buenos Aires: La Ley.

IVANEGA, M. M. (2000/2001). Consideraciones acerca del empleo público. Suplemento de Derecho Administrativo, pp. 764 ss.

Krotoschin, E. (1993). Manual de Derecho del Trabajo. Buenos Aires: Depalma.

LABAND, P. Le droit public de l'empire allemand, t. 2. Buenos Aires.

Marienhoff, M. (1990). Tratado de Derecho Administrativo. Buenos Aires: Abeledo Perrot. 
MEnÉndeZ, N. D. (2009/2010). La múltiple dimensión de la precariedad laboral: El caso de la Administración Pública en Argentina. Revista de Ciencias Sociales de Costa Rica, n. ${ }^{\circ}$ 128-129, pp. 119-136.

Muñoz de Bustillo Llorente, R. (2003). El empleo en la Unión Europea: situación, diagnóstico y políticas. En Responsa Iurisperitorum Digesta, vol. V, ed. José ÁNGEL GonZÁlez Delgado. España: Universidad Salamanca.

Palomar Olmeda, A. (2005). Organización y empleos públicos. Buenos Aires-Madrid: Editorial Ciudad Argentina.

Panebianco, A. (1996). Las Burocracias Públicas. En Gianfranco Pasquino (comp.). Manual de Ciencia Política. Salamanca: Alianza Editorial.

Parada, R. (2003). Derecho Administrativo II. Organización y empleo público. Madrid: Ediciones Jurídicas y Sociales.

Parada, R. (2003). Derecho del Empleo Público. Madrid: Ediciones Jurídicas y Sociales.

Pinto, J. (comp.) (1995). Introducción a la ciencia política. Buenos Aires: Eudeba.

RAmió Matas, C. (2004). Debilidad institucional y reforma de Estado en los países de América Latina, Diagnóstico y propuesta. En Responsa Iurisperitorum Digesta, vol. V, ed. José Ángel GonZÁlez Delgado. España: Ediciones Universidad de Salamanca.

RAZ, J. (1985). La autoridad del derecho. México: Unam.

Rivero Ortega, R. (2001). Introducción al Derecho Administrativo Económico. Salamanca.

Rivero Ortega, R. (1998). Administraciones públicas y derecho privado. Madrid: Ediciones Jurídicas y Sociales.

Rizzo, N. (2012). Los profesionales de Estado en Argentina: el caso del Instituto del Serivcio Exterior de la Nación (ISEN). Cuadernos de Política Exterior Argentina, n. ${ }^{\circ}$ 107, enero-marzo. Rosario.

Rodríguez Garabito, C. (2011). El derecho en América Latina. Un mapa para el pensamiento jurídico del siglo XXI. Buenos Aires: Siglo XXI.

Rosanvallon, P. (2009). La legitimidad democrática. Imparcialidad, reflexividad, proximidad. Buenos Aires: Manantial.

Salomoni, J. L. (1999). Teoría general de los servicios públicos. Buenos Aires: Ad-Hoc.

Sidicaro, R. (2003). La crisis del Estado y los actores políticos y socioeconómicos en la Argentina (1989-2001). Buenos Aires: Eudeba. 
Swampa, M. (2005). La sociedad excluyente. Argentina bajo el signo del neoliberalismo. Buenos Aires: Taurus.

SzWARCBERG, M. (2011). Clientelismo en democracia: lecciones del caso argentino. Nueva Sociedad, Argentina, n. ${ }^{\circ} 225$, enero.

VAllespín, F. (2000). Historia de la teoría política, vol. 6. Madrid: Alianza editorial.

VAlLESPín, F. (2000). Hacia un diagnóstico de la situación presente, pp. 21-90. En F. VAlLESPín, El futuro de la Política. España: Taurus. 